\title{
Chromosomal Heterogeneity of Various Mycoplasma hyopneumoniae Field Strains
}

\author{
JOACHIM FREY, ${ }^{*}$ ANDREAS HALDIMANN, AND JACQUES NICOLET \\ Institute for Veterinary Bacteriology, University of Bern, Länggassstrasse 122, \\ CH-3012 Bern, Switzerland
}

\begin{abstract}
Restriction enzyme digestion and field inversion gel electrophoresis were used to analyze the chromosomes of strains of Mycoplasma hyopneumoniae and the related organism Mycoplasma flocculare. The chromosome size for the $M$. hyopneumoniae type strain was calculated from individual fragments to be $1,011.3 \pm 32.9 \mathrm{kbp}$. The chromosomes of $M$. hyopneumoniae field strains were approximately the same size. The restriction patterns obtained for the chromosomes of phenotypically similar $M$. hyopneumoniae strains were quite different. Therefore, the species $M$. hyopneumoniae seems to be very heterogeneous. A field inversion gel electrophoresis analysis of the entire chromosomes allowed us to distinguish $M$. hyopneumoniae strains easily and hence to characterize further the species $M$. hyopneumoniae. The chromosome size for $M$. flocculare was calculated to be $988.3 \pm 39.5 \mathrm{kbp}$. Restriction enzyme $X$ hoI, which statistically should cut the $M$. hyopneumoniae chromosome frequently, did not cut the DNA of any of the $M$. hyopneumoniae strains but did digest $M$. flocculare DNA, indicating that there is a site-specific modification at CTCGAG which probably belongs to a restriction modification system in $M$. hyopneumoniae and is absent in $M$. flocculare.
\end{abstract}

Mycoplasma hyopneumoniae and Mycoplasma flocculare are commonly isolated from porcine respiratory tracts. $M$. hyopneumoniae is the primary agent of mycoplasmal pneumonia in swine (enzootic porcine pneumonia) $(11,19)$. This disease is common all over the world and causes large economic losses through retarded growth, poor food conversion, and increased susceptibility of swine to infection by other organisms (27). On the other hand, $M$. flocculare does not seem to be implicated directly in porcine mycoplasmal pneumonia (10). Studies on the taxonomic relationship between $M$. hyopneumoniae and $M$. flocculare have revealed only a few biochemical or cultural differences between these two mycoplasmas (26); the differentiation of these species is based on the results of serological tests, which are hampered by immunological cross-reactions between the species ( 1 , 23 ). The two species are clearly different at the genetic level, since DNA-DNA hybridization has revealed levels of sequence identity of only approximately $10 \%$ (10). No heterogeneity has been reported previously within the species $M$. hyopneumoniae, probably because of the limited tests which are available for differentiation of strains.

Most information on $M$. hyopneumoniae has been obtained from analyses of type strain ATCC 25934 (= NCTC $10110=J)(11,26)$, which has been reported to be indistinguishable from field strains on the basis of the results of growth inhibition, metabolic inhibition, and direct immunoelectrophoresis tests $(24,26)$. However, very little is known about possible differences in the chromosome structure, immunogenic factors, and virulence of $M$. hyopneumoniae strains. Although immunoblot analyses performed with rabbit hyperimmune serum or serum from experimentally infected pigs do not distinguish $M$. hyopneumoniae strains, Ro and Ross (23) have detected antigenetic diversity among various $M$. hyopneumoniae strains by two-dimensional immunoelectrophoresis. Stipkovits et al. (31) have reported that an early and strongly immunogenic protein, protein P36, is specific to $M$. hyopneumoniae and is conserved in many $M$. hyopneumoniae strains obtained from various geographic

\footnotetext{
* Corresponding author.
}

areas. Therefore, this protein is a useful marker for identification of $M$. hyopneumoniae strains and infections. It is essential to have a better understanding of the degree of genetic relatedness or variability among $M$. hyopneumoniae strains for studies on the taxonomy, epidemiology, and pathogenicity of this organism. Any analysis of genetic variability should be practical and reliable. In addition, fundamental knowledge concerning the structure and sizes of the chromosomes of the $M$. hyopneumoniae and the related nonpathogenic organism $M$. flocculare will be necessary to conduct further genetic studies on these species.

Restriction endonuclease fingerprinting analysis is a powerful technique for comparing DNAs of phenotypically and genetically similar organisms $(13,14,17)$. However, this method is often hampered by the large number of DNA bands which have to be resolved or by the fact that only bands in a certain size range, representing only a part of the genome, can be analyzed. Field inversion gel electrophoresis (FIGE) (29) is an ideal tool for separating large DNA fragments in analyses of bacterial chromosomes. In this study our objective was to use restriction enzyme digestion and FIGE to analyze the chromosome of the $M$. hyopneumoniae type strain and to use this methodology to compare this type strain with various $M$. hyopneumoniae field strains and $M$. flocculare strains. We took advantage of the relatively low $\mathrm{G}+\mathrm{C}$ contents $(33 \mathrm{~mol} \%)$ of the chromosomes of these two Mycoplasma species (30) and used restriction enzymes with GC-rich recognition sites to cut the chromosomes into approximately 20 large restriction fragments. This analysis permitted us to accurately calculate the sizes of the chromosomes of $M$. hyopneumoniae and $M$. flocculare and to investigate the genetic heterogeneity in various $M$. hyopneumoniae field strains.

\section{MATERIALS AND METHODS}

Strains and growth conditions. The porcine Mycoplasma strains used in this study are shown in Table 1 . The strains were grown in Friis medium $(10)$ at $37^{\circ} \mathrm{C}$ to the end of the exponential growth phase, which occurred when the $\mathrm{pH}$ of the medium was 6.8 (corresponding to a concentration of 
TABLE 1. Mycoplasma strains

\begin{tabular}{llll}
\hline \multicolumn{1}{c}{ Species } & \multicolumn{1}{c}{ Strain } & \multicolumn{1}{c}{ Origin } & Reference or source $^{a}$ \\
\hline$M$. hyopneumoniae & ATCC $25934^{\mathrm{T}}\left(=\mathrm{J}^{\mathrm{T}}\right)$ & United Kingdom & ATCC \\
$M$. hyopneumoniae & NCTC $10110^{\mathrm{T}}\left(=\mathrm{J}^{\mathrm{T}}\right)$ & United Kingdom & NCTC \\
$M$. hyopneumoniae & $\mathrm{JF} 184 \mathrm{a}^{\mathrm{T}}\left(=\mathrm{J}^{\mathrm{T}}\right)$ & United Kingdom & Canada (C. L'Ecuyer) \\
$M$. hyopneumoniae & EP 29 & France (M. Kobisch) & Field isolate \\
$M$. hyopneumoniae & BQ 14 & Switzerland & Field isolate (our laboratory) \\
$M$. hyopneumoniae & EP-S 924 & Switzerland & Field isolate (our laboratory) \\
$M$. hyopneumoniae & EP-S 938 & Switzerland & Field isolate (our laboratory) \\
$M$. hyopneumoniae & EP-S 939 & Switzerland & Field isolate (our laboratory) \\
$M$. hyopneumoniae & EP-S 946 & Switzerland & Field isolate (our laboratory) \\
$M$. hyopneumoniae & EP-S 223 & Denmark & NCTC \\
$M$. flocculare & NCTC $10143^{\mathrm{T}}\left(=\mathrm{Ms} 42^{\mathrm{T}}\right)$ & & \\
\hline
\end{tabular}

a ATCC, American Type Culture Collection, Rockville, Md.; NCTC, National Collection of Type Cultures, London, United Kingdom.

approximately $10^{8}$ cells per $\mathrm{ml}$ ). Chloramphenicol was then added to the growth medium at a concentration of $80 \mu \mathrm{g} / \mathrm{ml}$, and the cells were incubated for another $2 \mathrm{~h}$ before they were harvested in order to let replication forks terminate without the initiation of new rounds of replication $(16,22)$. The cells were harvested by centrifugation at $20,000 \times g$ for $20 \mathrm{~min}$, washed three times in phosphate-buffered saline $(10 \mathrm{mM}$ sodium phosphate [pH 7.0], $0.9 \% \mathrm{NaCl}$ ), resuspended in phosphate-buffered saline at a concentration of $3 \times 10^{9}$ cells per $\mathrm{ml}$, and kept frozen until they were used. The field isolates of $M$. hyopneumoniae were identified by using the growth inhibition test described by Clyde (7) and antisera against strain $\mathrm{J}^{\mathrm{T}}$ ( $\mathrm{T}=$ type strain) (11). The strains were also tested for the presence of protein P36, a common and specific antigenic protein of $M$. hyopneumoniae (31).

Southern hybridization of genomic DNA. Genomic DNAs of $M$. hyopneumoniae and $M$. flocculare were isolated as described previously (32). Aliquots (500 ng) of DNA were digested with EcoRI, separated on a $0.7 \%$ agarose gel in TBE buffer (28), and blotted onto a nitrocellulose membrane (Bio-Rad Laboratories, Richmond, Calif.), by using a Pharmacia model LKB 2016 VacuGene system according to the instructions of the supplier. The probes which we used were chromosomal DNAs of $M$. hyopneumoniae NCTC $10110^{\mathrm{T}}$ and $M$. flocculare $\mathrm{Ms} 42^{\mathrm{T}}$ that were digested with EcoRI and labeled with $\left[{ }^{32} \mathrm{P}\right] \mathrm{dCTP}(3,000 \mathrm{Ci} / \mathrm{mmol}$; Amersham $)$ by using the random priming method (8). Hybridizations were carried out at $37^{\circ} \mathrm{C}$ in $5 \times \mathrm{SSC}(1 \times \mathrm{SSC}$ is $0.15 \mathrm{M} \mathrm{NaCl}$ plus 0.015 $\mathrm{M}$ trisodium citrate [pH 7.0]) containing $5 \%$ polyethylene glycol $6000,0.5 \%$ sodium dodecyl sulfate, $50 \%$ formamide, and $100 \mu \mathrm{g}$ of denatured and sonified salmon sperm DNA per $\mathrm{ml}$. The filters were washed twice in $0.1 \times$ SSC $-0.1 \%$ sodium dodecyl sulfate at $50^{\circ} \mathrm{C}$, a temperature that corresponded to the melting temperature of DNA-DNA duplexes having approximately $85 \%$ sequence identity. The filters were exposed for 1 day at $-80^{\circ} \mathrm{C}$ on Fuji RX film by using an intensifying screen.

Preparation of chromosomal DNA in agarose blocks and FIGE. Mycoplasma cells were molded into blocks ( 1.5 by 5.5 by $4 \mathrm{~mm}$ ) of low-gelling low-melting-point (LGLM) agarose (Biofinex, Praroman, Switzerland) at a concentration of $4 \times$ $10^{9}$ cells per ml as described previously (22). The $\mathrm{Myco}$ plasma cells were then lysed by placing the blocks in ETS buffer $(10 \mathrm{mM}$ Tris- $\mathrm{HCl}, 500 \mathrm{mM}$ EDTA, $1 \% \mathrm{~N}$-laurosylsarkosine [catalog no. L-5125; Sigma]) containing $1 \mathrm{mg}$ of proteinase $\mathrm{K}$ (Sigma) per $\mathrm{ml}(\mathrm{pH} 8.0)$ at $50^{\circ} \mathrm{C}$ for $18 \mathrm{~h}$, and this was followed by incubation in TEP buffer $(10 \mathrm{mM}$ Tris- $\mathrm{HCl}, 1 \mathrm{mM}$ EDTA, $1 \mathrm{mM}$ phenylmethylsulfonyl fluoride; $\mathrm{pH} 8.0$ ) at $4^{\circ} \mathrm{C}$ for $18 \mathrm{~h}$. The blocks were then stored in
ETS buffer at $4^{\circ} \mathrm{C}$. The blocks were washed three times for $2 \mathrm{~h}$ in TE buffer (10 mM Tris- $\mathrm{HCl}, 1 \mathrm{mM}$ EDTA; $\mathrm{pH} 8.0$ ). DNA restriction digestion was performed by incubating the agar blocks in $250 \mu \mathrm{l}$ of the appropriate assay buffer (as recommended by the producer) containing $20 \mathrm{U}$ of restriction endonuclease (Boehringer Mannheim). The DNA was methylated in $250 \mu \mathrm{l}$ of TaqI methylase buffer (Biolabs, Beverly, Mass.) containing $2 \mathrm{mM}$ dithiothreitol, $0.1 \mathrm{mM}$ $S$-adenosylmethionine, and $30 \mathrm{U}$ of TaqI methylase.

We produced multimers of bacteriophage $\lambda$ CI857Sam 7 DNA (Boehringer Mannheim) to use as molecular size markers for DNA fragments by using the method of Bancroft and Wolk (2), taking care to thaw the DNA only once, just before multimerization and molding into agarose blocks. In addition, intact chromosomes of Saccharomyces cerevisiae YP148 (21) which were prepared by using the method of Bellis et al. (3) were used as size standards.

FIGE was performed as described by Carle et al. (5). Agarose gels $(0.8 \%)$ were run for $40 \mathrm{~h}$ in TBE buffer $(44.5$ $\mathrm{mM}$ Tris, $44.5 \mathrm{mM}$ sodium borate, $1 \mathrm{mM}$ EDTA; $\mathrm{pH} 8.0$ ) cooled to $15^{\circ} \mathrm{C}$ by using a voltage gradient of $4.0 \mathrm{~V} / \mathrm{cm}$. Pulse times were generated by using a model PPI-200 power inverter (MJ Research, Cambridge, Mass.). Preprogrammed pulse time ramps varying from 0.15 to $75 \mathrm{~s}$ forward and 0.05 to $25 \mathrm{~s}$ backward (according to the size range of DNA fragments to be analyzed) were generated by following the supplier's instructions. After electrophoresis, the gels were stained in ethidium bromide $(1 \mu \mathrm{g} / \mathrm{ml})$ for $30 \mathrm{~min}$, and then they destained in $1 \mathrm{mM} \mathrm{MgSO}_{4}$ for $60 \mathrm{~min}$ before photography under UV light. DNA fragments less than $20 \mathrm{kbp}$ long were analyzed by conventional agarose gel electrophoresis (28), using bacteriophage $\lambda$ DNA digested with HindIII as the size standard.

\section{RESULTS}

Chromosome sizes for $M$. hyopneumoniae and $M$. flocculare. Enzymatic digestion of the chromosomal DNA of $M$. hyopneumoniae ATCC $25934^{\mathrm{T}}$ with 35 restriction enzymes with recognition sequences of $6 \mathrm{bp}$ revealed that the enzymes that have only $\mathrm{G}$ and $\mathrm{C}$ residues in their recognition sequences generated 12 to 25 different restriction fragments (Table 2), while the numbers of fragments that were generated by the other enzymes were more than 50 . Restriction enzyme Xhol did not cut $M$. hyopneumoniae DNA. Digestion with Not I (recognition sequence, GCGGCCGC) resulted in two fragments. Since the fragments that were produced with ApaI were resolved best on our gel systems, we used this enzyme for further studies. The fragments of $M$. hyopneumoniae 
TABLE 2. Restriction enzymes that cut infrequently

\begin{tabular}{llcc}
\hline \multirow{2}{*}{ Enzyme } & Site & \multicolumn{2}{c}{ No. of fragments obtained with $^{a}:$} \\
\cline { 3 - 4 } & & $\begin{array}{c}\text { M. hyopneumoniae } \\
\text { ATCC 25934 }\end{array}$ & $\begin{array}{c}\text { M. } \text { flocculare }^{\mathrm{N}} \\
\text { NCTC 10143 }^{\mathrm{T}}\end{array}$ \\
\hline ApaI & GGGCCC & 12 & 11 \\
BssïII & GCGCGC & 18 & ND \\
EagI & CGGCCG & 12 & ND \\
NaeI & GCCGGC & 18 & ND \\
NarI & GGCGCC & 16 & ND \\
SacII & CCGCGG & 23 & ND \\
SmaI & CCCGGG & 25 & ND \\
\hline
\end{tabular}

${ }^{a}$ The $\mathrm{G}+\mathrm{C}$ content of both strains was $33 \mathrm{~mol} \%$. The mean \pm standard deviation number of fragments for $M$. hyopneumoniae ATCC $25934^{\mathrm{T}}$ was 18 \pm 4 . ND, not determined.

ATCC $25934^{\mathrm{T}}$ and $M$. flocculare NCTC $10143^{\mathrm{T}}$ chromosomal DNAs that were generated with $A p a I$ were subjected to analysis on different FIGE gels by using various FIGE parameters in order to obtain high resolution of the sizes of all of the fragments which are shown in Table 3. The fragment sizes were calculated from the results of 10 independent experiments, and the accuracy of the size determinations was estimated to be $5 \%$ or better. Addition of the lengths of the different fragments indicated that the sizes of the $M$. hyopneumoniae ATCC $25934^{\mathrm{T}}$ and $M$. flocculare NCTC $10143^{\mathrm{T}}$ chromosomes are $1,011.3 \pm 32.9$ and $988 \pm$ $39.5 \mathrm{kbp}$, respectively.

Chromosomal divergence. In order to estimate roughly the genetic similarity of the chromosomes of $M$. hyopneumoniae ATCC $25934^{\mathrm{T}}$, the field isolates, and $M$. flocculare, chromosomal DNAs of the strains were digested with EcoRI, separated by agarose gel electrophoresis, and analyzed by performing DNA-DNA hybridization experiments, using Southern blots and EcoRI-digested ${ }^{32} \mathrm{P}$-labeled chromosomal DNA of strain ATCC $25934^{\mathrm{T}}$ as the probe. All of the $M$. hyopneumoniae field strains produced hybridization patterns on autoradiograms that could not be distinguished from the pattern of the homologous type strain. In addition, no clear differences in the EcoRI restriction patterns of the various strains were observed because of the high number of bands.

TABLE 3. ApaI fragments of $M$. hyopneumoniae and M. flocculare

\begin{tabular}{|c|c|c|}
\hline \multirow[b]{2}{*}{ Fragment } & \multicolumn{2}{|c|}{ Size $(k b p)$ in: } \\
\hline & $\begin{array}{l}\text { M. hyopneumoniae } \\
\text { ATCC } 25934^{\mathrm{T}}\end{array}$ & $\begin{array}{l}\text { M. flocculare } \\
\text { NCTC } 10143^{\mathrm{T}}\end{array}$ \\
\hline A & $278.3 \pm 6.2$ & $245.0 \pm 4.1$ \\
\hline B & $154.0 \pm 4.3$ & $121.7 \pm 6.2$ \\
\hline $\mathrm{C}$ & $144.0 \pm 4.3$ & $106.7 \pm 6.2$ \\
\hline D & $117.0 \pm 2.2$ & $94.6 \pm 4.1$ \\
\hline $\mathrm{E}$ & $106.6 \pm 2.3$ & $80.7 \pm 4.1$ \\
\hline $\mathrm{F}$ & $72.3 \pm 5.4$ & $78.3 \pm 2.4$ \\
\hline G & $63.0 \pm 3.7$ & $73.3 \pm 2.3$ \\
\hline $\mathrm{H}$ & $26.0 \pm 1.4$ & $69.3 \pm 3.2$ \\
\hline I & $16.7 \pm 1.2$ & $49.0 \pm 3.7$ \\
\hline $\mathbf{J}$ & $15.5 \pm 1.0$ & $47.7 \pm 2.1$ \\
\hline $\mathrm{K}$ & $9.6 \pm 0.5$ & $22.0 \pm 1.1$ \\
\hline L & $8.3 \pm 0.4$ & \\
\hline
\end{tabular}

a The mean \pm standard deviation chromosome sizes of $M$. hyopneumoniae ATCC $25934^{\mathrm{T}}$ and $M$. flocculare NCTC $10143^{\mathrm{T}}$ are $1,011.3 \pm 32.9$ and 988.3 $\pm 39.5 \mathrm{kbp}$, respectively. The means and standard deviations were calculated from 10 independent experiments for $M$. hyopneumoniae and from 3 independent experiments for $M$. flocculare.
Since $M$. flocculare DNA had only a few bands that hybridized with $M$. hyopneumoniae, the level of sequence identity between the chromosomal DNAs of these two species was estimated to be less than $10 \%$.

A FIGE analysis of chromosomal DNAs that were digested with ApaI showed that there were clear differences in the restriction patterns of the various $M$. hyopneumoniae strains (Fig. 1). This method also showed that the restriction pattern for type strain $J$ was identical to the patterns for the two type strains obtained from culture collections, strains ATCC 25934 and NCTC 10110 (Fig. 1). Interestingly, strain JF $184 \mathrm{a}^{\mathrm{T}}$ which was a clone of strain $\mathrm{J}^{\mathrm{T}}$ (received from $\mathrm{P}$. Whittlestone) but had undergone a different number of passages in culture medium than the culture collection strains, contained an additional 125-kb ApaI fragment (Fig. 1) but lacked the 8-kb ApaI fragment (not visible on Fig. 1). Digestion with BstEII confirmed that strain JF $184 \mathrm{a}^{\mathrm{T}}$ contained additional DNA fragments compared with strains ATCC $25934^{\mathrm{T}}$ and NCTC $10110^{\mathrm{T}}$. The various field strains produced different $A p a$ I restriction patterns and could all be distinguished by the FIGE analysis. However, the field strains from Switzerland that were isolated by workers from our laboratory seemed to produce more homogeneous restriction patterns than the strains that had different geographical origins. The chromosome sizes of the different field strains were very similar to the chromosome size of the type strain (close to $1,000 \mathrm{~kb}$ ) (Fig. 1). The same results were obtained when we used restriction enzyme BstEII.

Site-specific modification of $M$. hyopneumoniae DNA. The DNAs of all of the $M$. hyopneumoniae strains that were tested in our study were completely resistant to digestion by $X$ hol, while $M$. flocculare DNA was fully digested and produced a large number of small fragments. XhoI restriction was sensitive to methylation of the $C$ residue in position 3 and the $A$ residue in position $5\left(\mathrm{CTC}^{+} \mathrm{GA}^{+} \mathrm{G}\right)$. Therefore, we used the restriction enzymes which contain the same "core" sequence (TCGA) in their recognition sequence as $X$ hoI (CTCGAG) and which are sensitive to A residue methylation. Both $M$. hyopneumoniae and $M$. flocculare DNAs were digested with restriction enzymes BstBI (TTCGAA), ClaI (ATCGAT), SalI (GTCGAC), and TaqI (TCGA). DNAs from $M$. hyopneumoniae and $M$. flocculare that were methylated by using TaqI methylase $\left(\right.$ TCGA $^{\mathrm{m}}$ ) were resistant to all of the restriction enzymes mentioned above (data not shown). It is worthwhile to note that an $M$. hyopneumoniae chromosome treated with XhoI or a chromosome from $M$. hyopneumoniae or $M$. flocculare treated with TaqI methylase and then incubated with any of the restriction enzymes mentioned above on FIGE analysis produced a band at approximately $1,000 \mathrm{~kb}$ that corresponded to the full-size chromosome. This might have represented chromosomal DNA that was randomly linearized once.

\section{DISCUSSION}

The techniques of pulsed-field gel electrophoresis, including FIGE and contour clamped homogeneous electric field electrophoresis, are suitable for determining the molecular sizes of large DNA fragments, particularly fragments in the range from 20 to $2,000 \mathrm{kbp}(4,5,13)$. Therefore, these techniques have been used to analyze and determine the genome sizes of various bacteria. Because of the low $G+C$ contents of mollicute DNAs, there has been concern about the value of these techniques for determining the chromosome sizes of Mycoplasma and Acholeplasma strains (18). 


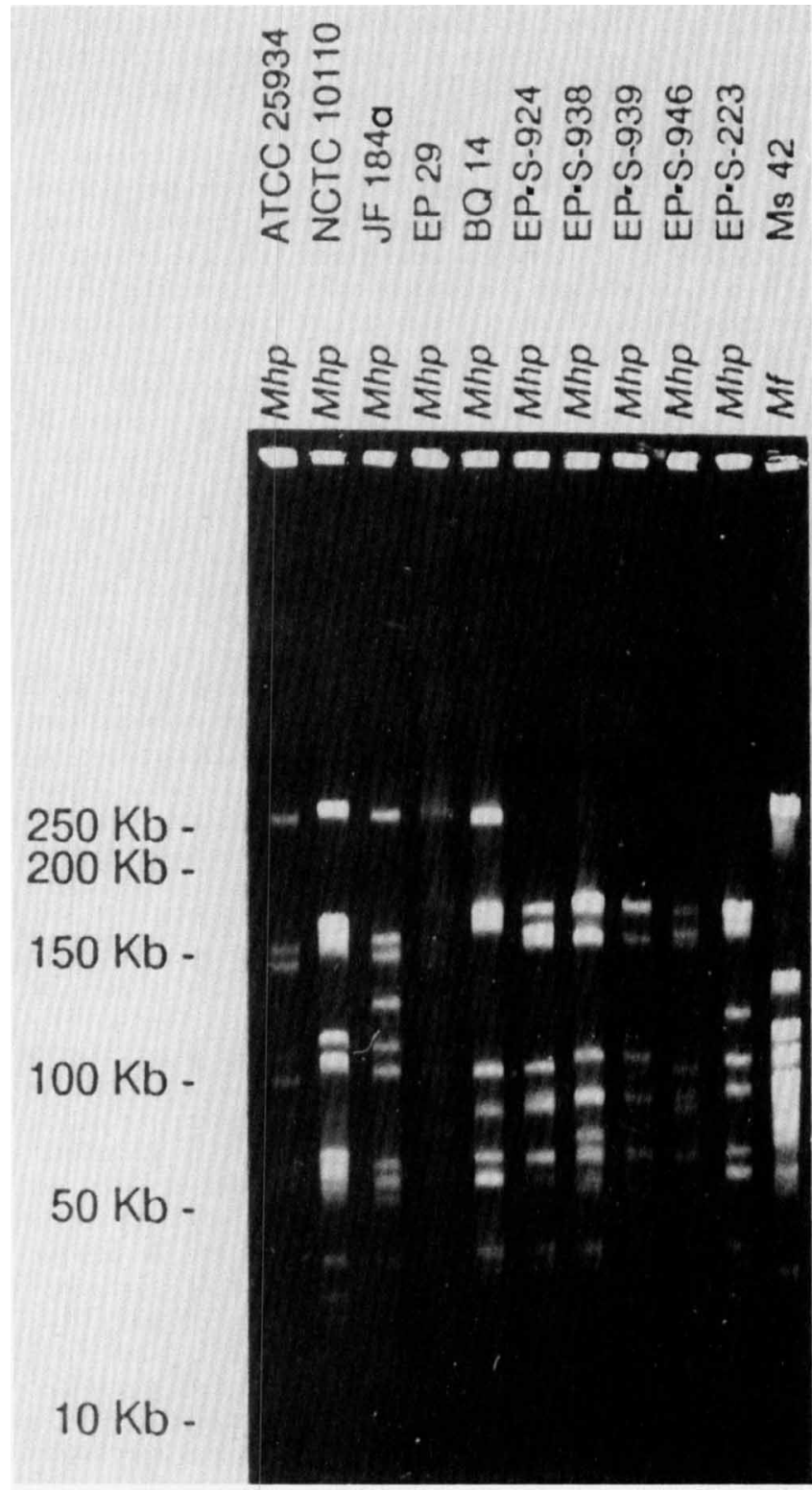

FIG. 1. Restriction enzyme profiles of $M$. hyopneumoniae strains and the $M$. flocculare type strain. The mycoplasmas were lysed in agarose blocks as described in the text and digested with ApaI, and the fragments were separated by FIGE on a $0.8 \%$ agarose gel (length, $25 \mathrm{~cm}$ ) by using model PPI-200 power inverter program 4. The sizes are indicated on the left and were determined by using bacteriophage lambda multimers. The calculated chromosome sizes for the $M$. hyopneumoniae strains were as follows: strain ATCC $25934^{\mathrm{T}}, 1,011.3 \pm 32.9 \mathrm{kbp}$; strain NCTC $10110^{\mathrm{T}}, 1,011.0 \pm 41.9$ kbp; strain JF $184 \mathrm{a}^{\mathrm{T}}, 1,142.4 \pm 38.2 \mathrm{kbp}$; strain EP $29,1,025.0 \pm$ $58.3 \mathrm{kbp}$; strain BQ 14, 1,069.2 $\pm 66.2 \mathrm{kbp}$; strain EP-S 924, $981.7 \pm$ $31 \mathrm{kbp}$; strain EP-S 938, $970.0 \pm 29 \mathrm{kbp}$; strain EP-S 939, $970 \pm 29.5$ kbp; strain EP-S 946, $992.5 \pm 33.4 \mathrm{kbp}$; strain EP-S 223, $955.7 \pm$ $30.6 \mathrm{kbp}$; and $M$. flocculare NCTC $10143,988 \pm 39.5 \mathrm{kbp}$. Mhp, $M$. hyopneumoniae; $M f, M$. flocculare; $\mathrm{Kb}$, kilobase pairs.

However, so far there have been no experimental data which prove that the low $\mathrm{G}+\mathrm{C}$ contents affect the migration of DNA fragments during PFGE. In contrast, various workers have successfully used PFGE techniques to estimate the sizes of full-length Mycoplasma and Acholeplasma chromo- somes that were linearized by gamma irradiation (20) or by partial restriction enzyme digestion (25).

The chromosome size for $M$. hyopneumoniae $\mathrm{J}^{\mathrm{T}}$ (= ATCC $25934^{\mathrm{T}}$ ), as calculated from $12 \mathrm{ApaI}$ restriction fragments, is $1,011.3 \pm 32.9 \mathrm{kbp}$ (Table 3 ) and corresponds well to the result obtained by Robertson et al. (25), who measured the linearized nonfragmented chromosome of $M$. hyopneumoniae ATCC 25095 (= VMRI-11). The size of the $M$. flocculare chromosome is $988.3 \pm 39.5 \mathrm{kbp}$ (calculated from 11 ApaI fragments) (Table 3). This is $100 \mathrm{kbp}$ larger than the value determined by Robertson et al. (25) for the nonfragmented $M$. flocculare Ms $42^{\mathrm{T}}$ (= ATCC $27716^{\mathrm{T}}$ ) chromosome. The difference in the two values could have been due to the fact that the strain used by Robertson et al. (25) (strain ATCC $27716^{\mathrm{T}}$ ) had been propagated and recloned under different growth conditions and for a different number of generations than the strain used in our study (strain NCTC $10143^{\mathrm{T}}$. [= ATCC $27399^{\mathrm{T}}$ ]); such differences could have caused chromosome rearrangements in one of the strains.

The different restriction enzymes with 6-bp recognition sequences consisting of exclusively $\mathrm{G}$ and $\mathrm{C}$ residues which we used cut the $M$. hyopneumoniae chromosome an average of 18 times (Table 2). Assuming a $\mathrm{G}+\mathrm{C}$ content of $33 \mathrm{~mol} \%$ (30), we expected that the $M$. hyopneumoniae $1,000-\mathrm{kbp}$ chromosome would be cut 18 times by enzymes that recognize a 6-bp sequence that is composed of only $G$ and $C$ residues (number of cuts $=$ chromosome size [in bp] $\times$ $\left.[\mathrm{G}+\mathrm{C}]^{6} \times[0.5]^{6}\right)$. This value correlates well with the mean number of fragments that were obtained experimentally (Table 2).

The restriction patterns shown in Fig. 1 were different for most $M$. hyopneumoniae strains. Although the strains that were isolated by workers from our laboratory in Switzerland could be distinguished, these strains shared a number of fragments. The differences among the strains isolated in different countries were much larger. The sizes of the chromosomes of most of the $M$. hyopneumoniae strains that were analyzed were close to $1,000 \mathrm{kbp}$; the exception was strain JF $184 \mathrm{a}^{\mathrm{T}}$, whose chromosome was approximately 100 kbp larger (Fig. 1). It is interesting that the cultures of strain $\mathrm{J}^{\mathrm{T}}$ that were obtained from two culture collections (strains ATCC $25934^{\mathrm{T}}$ and NCTC $10110^{\mathrm{T}}$ ) produced identical restriction patterns, while strain JF $184 \mathrm{a}^{\mathrm{T}}$, which is strain $\mathrm{J}^{\mathrm{T}}$ culture that was obtained directly from $\mathrm{P}$. Whittlestone, had a $125-\mathrm{kbp}$ ApaI fragment instead of the 8.3-kbp fragment. We assumed that the chromosome of strain $\mathrm{JF} 184 \mathrm{a}^{\mathrm{T}}$ had undergone a duplication of a 117-kbp chromosomal fragment or that the strain $\mathrm{J}^{\mathrm{T}}$ cultures that were deposited in the culture collections had undergone a deletion of $117-\mathrm{kb}$ during passage or recloning. A similar chromosomal rearrangement might also have occurred in one of the two culture collection cultures of type strain Ms $42^{\mathrm{T}}$, and this could have led to the difference in chromosome sizes described above. The finding that the chromosomes of $M$. hyopneumoniae strains are heterologous is surprising. Some variations, such as the differences among strains NCTC $10110^{\mathrm{T}}$, JF $184 \mathrm{a}^{\mathrm{T}}$, and ATCC $25934^{\mathrm{T}}$, which all originate from the strain $\mathrm{J}^{\mathrm{T}}$ isolate, indicate that the chromosome of $M$. hyopneumoniae undergoes frequent chromosomal rearrangements. These arrangements could be due to repetitive (insertion sequence-like) elements that have recently been detected in $M$. hyopneumoniae $(9,12)$ and might play a role in control of gene expression and host or medium adaptation. However, other variations in the chromosomal structure seem to be due to larger phylogenetic differences since we observed clonal homogeneity of the strains that were isolated in Switzerland, 
a small geographical area, and rather strong heterogeneity of strains that originated from distant places. However, the chromosome differences do not seem to affect the few phenotypes that are currently used for identification of $M$. hyopneumoniae. It should be noted that strains ATCC $25934^{\mathrm{T}}$ and $\mathrm{BQ} 14$, which produce very different ApaI restriction patterns, seem to have very different virulence properties when they are used in experimental infections (13a). A similar situation has been observed with Leptospira infections of pigs, in which differences in virulence are associated with differences in the chromosomal restriction patterns of strains which could not be distinguished by other methods (7a).

Restriction enzyme $X$ hol does not cut the chromosomal DNAs of the $M$. hyopneumoniae strains which we analyzed, although on the basis of statistics we expected it to cut the chromosome 114 times. In contrast, $M$. flocculare DNA was digested by XhoI. Therefore, believe that $M$. hyopneumoniae DNA is modified (probably methylated) at the XhoI site. Our results show that the modification must be specific to the XhoI recognition site. Therefore, $M$. hyopneumoniae might have its own restriction modification system. This modification is different from the more frequent site-specific methylation at GATC which has been described in $M$. hyopneumoniae (6) and resembles the methylation induced by the Escherichia coli dam gene. It should be noted that Pyle et al. (21) have found that the chromosome of $M$. hyopneumoniae is cut only once by XhoI, resulting in a 1,140 -kbp fragment. On the basis of our results, we believe that the single $1,140-\mathrm{kbp}$ fragment might have been created by linearization of the chromosome at random during an incubation reaction and not by site-specific cleavage.

In summary, we found that the chromosomes of $M$. hyopneumoniae strains are quite different. Restriction enzyme digestion with infrequently cutting enzymes and subsequent analysis by FIGE is a simple and reliable method for distinguishing different $M$. hyopneumoniae strains. This finding is important for studies of the taxonomy of $M$. hyopneumoniae, as well as for epidemiological studies of $M$. hyopneumoniae outbreaks. In view of the genetic diversity of $M$. hyopneumoniae strains, specific diagnostic tools, such as polymerase chain reaction amplification based on nucleotide sequences of randomly chosen DNA fragments, need to be evaluated with a large number of strains before they can be proposed as safe methods for detecting $M$. hyopneumoniae infections. Site-specific modification at CTCGAG, which is probably a component of a restriction modification system, seems to be common to $M$. hyopneumoniae strains and is not found in $M$. flocculare.

\section{ACKNOWLEDGMENTS}

We are grateful to Ruud Segers (Boxmeer, The Netherlands) for critical reading of the manuscript, to Jacques Falquet (University of Geneva) for valuable suggestions concerning the FIGE technique, to Lloyd Finch (University of Melbourne) for the gift of $S$. cerevisiae YP148, and to M. Hämmerli (Institute for Mathematical Statistics, University of Bern).

\section{REFERENCES}

1. Armstrong, C. M., M. J. Freeman, and L. Sands-Freeman. 1978. Cross-reactions between Mycoplasma hyopneumoniae and $M y$ coplasma flocculare. Practical implications for the serodiagnosis of mycoplasmal pneumonia of swine. Isr. J. Med. Sci. 23:654-656.

2. Bancroft, I., and C. P. Wolk. 1988. Pulsed homogeneous orthogonal field gel electrophoresis (PHOGE). Nucleic Acids Res. 16:7405-7418.
3. Bellis, M., M. Pagès, and G. Roizès. 1987. A simple and rapid method for preparing yeast chromosomes for pulse field gel electrophoresis. Nucleic Acids Res. 15:6749.

4. Cantor, C. R., C. L. Smith, and M. K. Mathew. 1989. Pulsed field gel electrophoresis of very large DNA molecules. Annu. Rev. Biophys. Chem. 17:287-304.

5. Carle, G. F., M. Frank, and M. V. Olson. 1986. Electrophoretic separations of large DNA molecules by periodic inversion of the electric field. Science 232:65-68.

6. Chan, H. W., and R. F. Ross. 1984. Restriction endonuclease analyses of two porcine Mycoplasma deoxyribonucleic acids: sequence-specific methylation in the Mycoplasma hyopneumoniae genome. Int. J. Syst. Bacteriol. 34:16-20.

7. Clyde, W. A. 1983. Growth inhibition tests. Methods Mycoplasmol. 1:405-417.

7a.Ellis, W. A., J. M. Montgomery, and A. B. Thiermann. 1991. Restriction endonuclease analysis as a taxonomic tool in the study of pig isolates belonging to the australis serogroup of Leptospira interrogans. J. Clin. Microbiol. 29:957-961.

8. Feinberg, A. P., and B. Vogelstein. 1983. A technique for radiolabelling DNA restriction endonuclease fragments to high specific activity. Anal. Biochem. 132:6-13.

9. Ferrell, R. V., M. B. Heidari, K. S. Wise, and M. A. McIntosh. 1989. A Mycoplasma genetic element resembling prokaryotic insertion sequences. Mol. Microbiol. 3:957-967.

10. Friis, N. F. 1973. The pathogenicity of Mycoplasma flocculare. Acta Vet. Scand. 14:344-346.

11. Goodwin, R. F. W., A. P. Pomeroy, and P. Whittlestone. 1965. Production of enzootic pneumonia in pigs with a mycoplasma. Vet. Rec. 77:1247-1249.

12. Harasawa, R., K. Koshimizu, O. Takeda, T. Uemori, K. Asada, and I. Kato. 1991. Detection of Mycoplasma hyopneumoniae DNA by the polymerase chain reaction. Mol. Cell. Probes 5:103-109.

13. Heller, C., and F. M. Pohl. 1989. A systematic study of field inversion gel electrophoresis. Nucleic Acids Res. 17:5589-6005.

13a.Kobisch, M. (Ploufragen, France). Personal communication.

14. Kristiansen, B. E., B. Sörensen, B. Bjorvatn, E. S. Falk, E. Fosse, K. Bryn, L. Fröholm, P. Gaustad, and K. Bovre. 1986. An outbreak of group B meningococcal disease: tracing the causative strain of Neisseria meningitidis by DNA fingerprinting. J. Clin. Microbiol. 23:764-767.

15. Kuijper, E. J., J. H. Oudbier, W. N. H. M. Stuif-Bergen, A. Jansz, and H. C. Zanen. 1987. Application of whole-cell DNA restriction endonuclease profiles to the epidemiology of Clostridium difficile-induced diarrhea. J. Clin. Microbiol. 25:751753.

16. Lark, K. G. 1973. Initiation and termination of bacterial deoxyribonucleic acid replication in low concentrations of chloramphenicol. J. Bacteriol. 113:1066-1069.

17. McInnes, J., J. Borr, M. Massoudi, and S. Rosendal. 1990. Analysis of southern Ontario Actinobacillus (Haemophilus) pleuropneumoniae isolates by restriction endonuclease fingerprinting. Can. J. Vet. Res. 54:244-250.

18. Maniloff, J. 1989. Anomalous values of Mycoplasma genomes sizes determined by pulse-field gel electrophoresis. Nucleic Acids Res. 17:1268.

19. Maré, C. J., and W. P. Switzer. 1965. Mycoplasma hyopneumoniae, a causative agent of virus pig pneumonia. Vet. Med. 60:841-845.

20. Neimark, H. C., and C. S. Lange. 1990. Pulse-field electrophoresis indicates full-length mycoplasma chromosomes range widely in size. Nucleic Acids Res. 18:5443-5448.

21. Pyle, L. E., L. N. Corcoran, B. G. Cocks, A. D. Bergemann, J. C. Whitley, and L. R. Finch. 1988. Pulse field electrophoresis indicates larger-than-expected sizes for mycoplasma genomes. Nucleic Acids Res. 16:6015-6025.

22. Pyle, L. E., and L. R. Finch. 1988. Preparation and FIGE separation of infrequent restriction fragments from Mycoplasma mycoides DNA. Nucleic Acids Res. 16:2263-2268.

23. Ro, L. H., and R. F. Ross. 1983. Comparison of Mycoplasma hyopneumoniae strains by serologic methods. Am. J. Vet. Res. 44:2087-2094. 
24. Roberts, D. H., and T. W. A. Little. 1970. Serological studies in pigs with Mycoplasma hyopneumoniae. J. Comp. Pathol. 80: 211-220.

25. Robertson, J. A., L. E. Pyle, G. W. Stemke, and L. R. Finch. 1990. Human ureaplasmas show diverse genome sizes by pulsed-field electrophoresis. Nucleic Acids Res. 18:1451-1455.

26. Rose, D. L., J. G. Tully, and R. G. Wittler. 1979. Taxonomy of some swine mycoplasmas: Mycoplasma suipneumoniae Goodwin et al. 1965, a later, objective synonym of Mycoplasma hyopneumoniae Mare and Switzer 1965, and the status of Mycoplasma flocculare Meyling and Friis 1972. Int. J. Syst. Bacteriol. 29:83-91.

27. Ross, R. F. 1986. Mycoplasmal diseases, p. 469-483. In A. D. Leman, B. Straw, R. D. Glock, W. L. Mengeling, T. H. C. Penny, and E. Scholl (ed.), Diseases of swine, 5th ed. Iowa State University Press, Ames.

28. Sambrook, J., E. F. Fritsch, and T. Maniatis. 1989. Molecular cloning. A laboratory manual. Cold Spring Harbor Laboratory
Press, Cold Spring Harbor, N.Y.

29. Schwartz, D. C., and C. R. Cantor. 1984. Separation of yeast chromosome-sized DNAs by pulsed field gradient gel electrophoresis. Cell 37:67-75.

30. Stemke, G. W., D. J. McIntyre, K. L. Roy, M. E. Stemler, and J. A. Robertson. 1985. Guanine-plus-cytosine compositions of and deoxyribonucleic acid hybridization comparisons between Mycoplasma hyopneumoniae and Mycoplasma flocculare. Int. J. Syst. Bacteriol. 35:527-529.

31. Stipkovits, L., J. Nicolet, A. Haldimann, and J. Frey. 1991. Use of antibodies against the P36 protein of Mycoplasma hyopneumoniae for the identification of $M$. hyopneumoniae strains. Mol. Cell. Probes 5:451-457.

32. Strasser, M., J. Frey, G. Bestetti, M. Kobisch, and J. Nicolet. 1991. Cloning and expression of a species-specific early immunogenic $36-\mathrm{kDa}$ protein of Mycoplasma hyopneumoniae in Escherichia coli. Infect. Immun. 59:1217-1222. 